are less likely to produce reactions in certain high risk patients such as those with asthma, cardiac or renal failure, or a history of such reactions (19 March, p 809). He states, quite rightly, that these media are still considerably dearer than the older agents but does not mention the quantity necessary to produce adequate radiographs.

Using only half the currently recommended dose $(25 \mathrm{ml}$ instead of $50 \mathrm{ml}$ ), we have shown that in most patients this amount produces diagnostically acceptable urograms. ${ }^{1}$ Our conclusion was that if this regimen is followed it should prove possible to use the safer media for all patients and that although this would cost more than at present it should prevent the rare serious complications including the occasional death.

\section{MYer Goldman}

BRIAN EYFS

Departments of Radiology,

Fazakerley and Walton Hospitals,

Liverpool L9

1 Eyes BE, Goldman M, Nixon TE, Scally J, Brown A. Low dose low osmolar intravenous urography. Clin Radiol 1987;38: 403-5.

\section{Early growth in diabetic pregnancy}

SIR,-Dr Minna Bloch Petersen and colleagues (27 February, p 598) seek to show that delayed fetal growth in early pregnancy, which they report as being more common in the offspring of diabetic women, is a cause of developmental delay at age 4 .

In drawing this conclusion, however, they ignore a crucial part of their own data-namely, that only $5 \%$ of the diabetic mothers were educated to college standard compared with $18 \cdot 6 \%$ of the non-diabetic women. Since the only significant difference between the Denver test scores of the two groups of children was in language and speech development, it seems at least as likely that this was related to levels of sophistication in language use in the mothers as it was to intrauterine growth delay. It is, of course, true that there was apparently a difference within the diabetic group between those children in whom growth was delayed and those in whom it was not; the numbers of children in these two groups who failed the Denver test, however, were small (eight and two respectively), so that the probability of a type 2 error must be high if some other factor, such as maternal educational level, is operating.

Royal Liverpool Hospital,

Liverpool L7 8XP

ROGER A FISKEN

AUTHOR'S REPLY,-Dr R A Fisken is right in his remarks on the educational difference between diabetic and non-diabetic mothers $(2.4 \%$ and $18.6 \%$ educated at college level respectively).

In our study we found that as a group the children of diabetic mothers scored only slightly (and not significantly) worse than those of nondiabetic mothers. Secondly, the results of the Denver developmental screening test were not associated with the level of education of the mothers. Thirdly, the children of diabetic mothers with normal early fetal growth had scores very similar to those of the children of non-diabetic mothers, and no significant difference was found in language and speech development (the difference in the educational level of the mothers in the two groups being the same as mentioned above) Finally, the poor performance in the Denver developmental screening test in the diabetic group was apparently confined to those children who had been small in early fetal life. Only $67 \cdot 7 \%$ of these children had normal test scores and $23.5 \%$ failed in language and speech, compared with $92 \%$ and
$4 \%$ respectively of the children with normal discuss their data in the context of prevention by early fetal growth. The educational level of the two groups of diabetic mothers did not differ significantly.

We are well aware of the small number of children failing in language and speech and are aware that factors other than the mother's level of education may be operating-for example, different types of kindergartens. The overall test result of the two diabetic groups based on 34 and 50 children indicates, however, that early fetal growth delay may influence later development.

MinNa Bloch Petersen

Rigshospitalet,
Copenhagen $\emptyset$,

Copenhagen $\emptyset$
Denmark

HIV infection: risks of false positive serology

SIR,-Professor A A Glynn and Dr P P Mortimer (5 March, p 714) are right to emphasise that most commercially available HIV antibody tests are both highly sensitive and highly specific. If two different systems are used the risk of a false positive is about 1 in 40000 and if three different systems are used about 1 in 1 million.

Nevertheless, most virologists concerned in rubella antibody screening have encountered patients who have been reported as having rubella antibodies but have subsequently acquired rubella in pregnancy. In most cases this error has not been due to any failure of test systems or to loss of rubella antibodies but has been the result of other factors. ${ }^{12}$ These include, for example, incorrect labelling of blood containers in outpatient departments, technical errors, perhaps due to the interruption of a busy medical laboratory scientific officer performing the test, or even the issuing of an incorrect report due to a clerical error.

In view of the serious medicolegal consequences as well as the distress which may result from a false positive HIV test, we recommend that the risks should be minimised by issuing only a preliminary report when a serum sample is found to be positive by three tests. A final report can then be issued when the results have been confirmed by testing an additional serum sample from the same patient.

Since we routinely perform tests three times a week (or immediately in an emergency) and as clinicians can readily make arrangements to have their patients retested within a few days, our system need not result in there being undue delay before a final report is issued.

Felicity Nicholson JENNIFER M BEST J E BANATVALA

Department of Virology,

St Thomas's Hospital,

St Thomas's Hospit
London SE1 7EH

1 Best JM, Welch JM, Baker DA, Banatvala JE. Maternal rubella at St Thomas' Hospital in 1978 and 1986: support for augmenting the rubella vaccination programme. Lancet 1987;ii:88-90.

2 Miller CL, Miller E, Waight PA. Rubella susceptibility and the continuing risk of infection in pregnancy. $\mathrm{Br}$ Med $\mathcal{f}$ continuing risk

\section{The use of varicella vaccine in Britain}

SIR,-Drs Carol Joseph and Norman Noah provide valuable information on the clinical impact of varicella in Britain (5 March, p 673). They rightly point out that varicella accounts for a higher mortality than mumps, which we are about to attempt to prevent with the combined measlesmumps-rubella vaccine, but seem reticent to

\section{vaccination.}

We agree that a mass vaccination programme using the live varicella vaccine cannot be advocated until the questions of safety and long term efficacy have been resolved. A cost-benefit analysis ${ }^{1}$ has shown a benefit ratio of 7:1 for mass vaccination in the USA, but this benefit was mainly derived from costs to the family arising from the home care of sick children, not savings on medical costs. Since social conditions in Britain are different the financial argument will be strong only if the cost of the vaccine is comparable with that of other vaccines.

The most interesting dilemmas for licensing authorities relate to the long term effects of the vaccine on the epidemic pattern of varicella and on herpes zoster. Recent reports have shown that the vaccine virus can become latent and cause zoster, ${ }^{2}$ even in healthy vaccinees, ${ }^{3}$ although probably less frequently than wild type virus. More intriguingly, vaccination may not always protect from superinfection with wild type varicella zoster virus, which later can cause zoster. ${ }^{2}$ Paradoxically, only the experience gained through more general use of the vaccine will provide the necessary information about its long term effects on varicella and zoster.

The case for vaccination of immunocompromised patients is totally different. This is a steadily increasing group of patients who carry a high risk of life threatening complications associated with varicella. ${ }^{4}$ Undoubtedly, it is preferable to prevent these complications by vaccination rather than to rely on postexposure prophylaxis and treatment with zoster immune globulin or acyclovir. In fact, the vaccine is also effective for postexposure prophylaxis up to four days after contact. ${ }^{5}$

The vaccine has now been used in immunocompromised patients for over 10 years and has proved to be both safe and effective. ${ }^{6}$ Our own experience with this vaccine ${ }^{7}$ in paediatric oncology patients is that individual responses vary greatly but even in those with poor responses the vaccine appears to confer considerable protection. Good antibody concentrations have been maintained for over six years in some of our vaccinees after a single vaccine dose, although about $40 \%$ have shown poor or rapidly waning responses. Regular monitoring of immunity, combined with a booster vaccination, is therefore necessary.

It may not be a perfect vaccine but it is the best we have, and, while mass vaccination cannot be advocated on present evidence, there is no doubt that selected high risk groups would greatly benefit from this vaccine, particularly children with malignancies. The problem for British paediatricians who manage immunocompromised children is that the vaccine is not freely available here. The relevant authorities should give serious thought to licensing the varicella vaccine for selective use, as is done in several European countries and shortly will be in the United States.

H O KANGRO R B HEATH

Department of Virology,

St Bartholomew's Hospital,

London EC1A 7BE

1 Preblud SR, Orenstein WA, Koplan JP, Bart KJ, Hinman AR. A benefit cost analysis of a childhood varicella vaccination benefit cost analysis of a childhood varicella vaccing
programme. Postgrad Med f 1985;61(suppl 4):17-22.

2 Lawrence R, Gershon AA, Holzman R, Steinberg SP. The risk of zoster after varicella vaccination in children with leukemia. N Engl f Med 1988;318:543-8.

Plotkin SA. Hell's fire and varicella-vaccine safety. $N$ Engl $\mathcal{F}$ Med 1988;318:573-5. 1986;78(suppl):728-35.

5 Takahashi M, Hayakawa Y, Shiraki K, Yamanishi K, Asano Y, Ozaki T. Attenuation and laboratory markers of the Oka-strain
varicella-zoster virus. Postgrad Med f 1985;61(suppl 4):37-46. 6 varicella-zoster virus. Postgrad Med f 1985;61(suppl 4):37-46. varicella vaccine. Postgrad Med F 1985;61(suppl 4):113-20.
Preblud SR. Varicella: complications and costs. Pediatrics 